\section{Family-Centered Care}

Sylvie Naar-King

Detroit, MI, USA

\section{Synonyms}

Collaborative care

\section{Definition}

An "approach to the planning, delivery, and evaluation of health care that is grounded in mutually beneficial partnerships among health care patients, families, and providers" with the core concepts of "dignity and respect, information sharing, participation and collaboration" (Institute of Family-Centered Care). Practical examples including having the family attend team conferences and asking families about the desirability or feasibility of treatment options so that they are actively involved in decisionmaking. See Naar-King and Donders (2006) for a review of outcomes.

\section{Cross-References}

> Discharge Planning

- Family-Team Conference

- Patient-Family Education

\section{References and Readings}

Institute of Family Centered Care. Retrieved on 10 Aug 2008 from www.familycenteredcare.org/faq.html

Naar-King, S., \& Donders, J. (2006). Pediatric familycentered rehabilitation. In Treating neurodevelopmental disabilities. New York: Guilford Publications. 